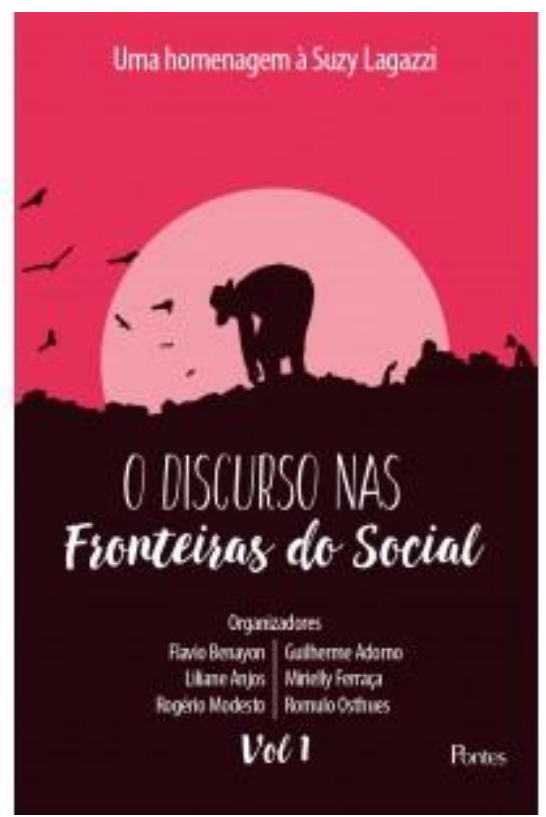

\title{
Suzy Lagazzi ou um guia à Análise de Discurso
}

\section{Suzy Lagazzi or a guide to Discourse Analysis}

Matheus França Ragieviczı

ORCID: https://orcid.org/0000-0002-1417-455X

Resumo: Dedicamo-nos a apresentar, no presente texto, "O discurso nas fronteiras do social volume 1", livro realizado em homenagem à Suzy Lagazzi, docente no Departamento de Linguística do Instituto de Estudos da Linguagem (IEL) da UNICAMP e pesquisadora atuante no Laboratório de Estudos Urbanos (LABEURB) da mesma universidade. Os artigos presentes na coletânea são produções de orientandos, orientados e companheiros de sua trajetória intelectual. Refletindo a potência de formulação teórica da autora, os idealizadores da homenagem traçam com rigor a contribuição de Lagazzi para Análise de Discurso. Um guia indispensável para os iniciantes e/ou aspirantes aos estudos do discurso e também àqueles que desejam encontrar uma presença teórica singularmente brasileira no terreno da Análise do Discurso.

Palavras-chave: Análise de Discurso; Lagazzi; Discurso; Materialidades significantes; Juridismo.

Abstract: In this review we presented the book "Discourse on social boundaries - volume 1", produced in honour of Suzy Lagazzi, professor at IEL (Institute of Language Studies) as so researcher at LABEURB (Urban Studies Laboratory) in UNICAMP (University of Campinas). The articles in volume 1 were written by Lagazzi's students, former students and companions of his intellectual trajectory. Showing the researcher's theoretical formulation power, those who honour Suzy in the book, rigorously present her contribution to Discourse Analysis. No doubt, Volume 1 is an indispensable guide for Discourse Analysis readers.

Key-words: Discourse Analysis; Lagazzi; Discourse; Significant materiality; Juridism.

1 Mestre e Doutorando em Letras no Programa de Pós-Graduação em Letras (PPGLET), da Universidade Federal do Paraná (UFPR). E-mail: matheusfrancar@gmail.com. 
O discurso nas fronteiras do social, livro publicado recentemente (2019) pela Editora Pontes, em dois volumes, traz ao leitor a presença de uma obra que destaca, ressoa e compila os pilares da trajetória intelectual de Suzy Lagazzi na Análise de Discurso. Lagazzi, renomada professora do Departamento de Linguística do Instituto de Estudos da Linguagem (IEL) da UNICAMP e pesquisadora atuante do Laboratório de Estudos Urbanos (LABEURB) dessa mesma instituição, fez emergir do seu caminho teórico não apenas triunfos pessoais, mas contribuições elementares que coincidem com o enraizamento da Análise de Discurso (AD) como teoria e modo, sui generis, de teorizar a linguagem no campo dos estudos linguísticos. Não é por menos que a homenagem prestada por aqueles que atravessaram sua trajetória, sejam orientandos, orientados ou companheiros intelectuais de longa data, instaura singularmente uma reconstituição do seu percurso pelo discurso. Percurso que é explorado com afeto, gratidão e sabedoria no primeiro volume, objeto da presente resenha. Portanto, apresentar a obra e os textos que a compõem, impõe-se como provocação; no movimento de resgate ao fio que (des)borda os artigos, nos deparamos com uma escrita em tinta viva, na qual o saber da produção discursiva posta sob o olhar de quem lê Suzy, de quem é afetado por Suzy, de quem é Suzy, absorve todo destaque. Manter esse cintilar é nosso desafio.

Guilherme Adorno, Rogério Modesto, Mirielly Ferraça, Flávio Benayon, Liliane Anjos e Rômulo Osthues encabeçam a homenagem e a organização do volume 1, composto por 13 artigos. Os autores que prestam tributo a Suzy no primeiro volume, mantêm, para além da relação institucional, um laço de afeto com a homenageada. Referir essa relação é encontrar os passos para leitura; o afeto, fio condutor, ecoa e reafirma o percurso teórico, analítico e político de Suzy Lagazzi. Incluo propositalmente o político, porque, afinal, em nossa formação social imbricar a diferença do social por um campo desestabilizador como a AD pecheutiana é afrontar um establishment que se produz nas instituições jurídicas, políticas e acadêmicas. Portanto, para falar sobre Suzy as vozes dos autores são divididas em três áreas temáticas, a saber, $O$ político e o jurídico, $A$ imbricação de diferentes materialidades significantes e Resistência simbólica.

$\mathrm{Na}$ Parte I, O político e o jurídico, o livro conta com as contribuições de Eni Puccinelli Orlandi, Flávio da Rocha Benayon, Solange Leda Gallo, Olimpia MalufSouza, Guilherme Adorno e Carolina Rodríguez-Alcalá. Destaca-se a retomada do trabalho inaugural de Suzy, isto é, sua reflexão sobre o juridismo que resultou em sua dissertação de mestrado e o livro derivado deste: $O$ desafio de dizer não (1988). O 
cotidiano insurge como objeto nodal, sendo atribuído à Suzy o papel de desbravá-lo quando muito pouco se havia produzido, teorizado e analisado a seu respeito.

Presidindo o começo da seção, há o texto A secretária: um obstáculo ao exercício dos Direitos Humanos? Cotidiano e burocracia de autoria de Eni Puccinelli Orlandi. Mentora de Suzy, Eni faz sentir, em sua reflexão, a atualidade do acontecimento que atravessa o caminho entrecruzado por ambas. Conservando as afinidades, Orlandi produz um texto na tênue relação do juridismo e da temática dos direitos humanos. O ponto de partida é o relato de Orlandi, no qual a autora narra a situação em que, por infortúnio, comprou um móvel defeituoso e tentou recorrer a seu direito de trocá-lo. O trâmite passa por várias secretárias que ouvindo a demanda da solicitante, colocam o direito à serviço dos entraves da burocracia. Orlandi considera o ocorrido como parte do discurso cotidiano, por isso, faz sua análise num duplo movimento: reavendo as questões de Suzy e colocando em relevo a injustiça do aparato burocrático. Eni deixa saber que "[...] faz parte da minha ética não deixar sem resposta as injustiças [...]” (ORLANDI, 2019, p. 26), assentando sua reflexão na direção de questionar a evidência do ordinário do sentido. Orlandi retoma de $S u z y$, a tese do juridismo, entendido como o que é:

[...] instaurado pelo senso comum no cotidiano das relações interpessoais, permitindo a atribuição de direitos e deveres, responsabilidades, cobranças e justificativas. Seu funcionamento se dá no nível do não dito, do implícito, constituindo-se em uma intertextualidade da instância jurídica, do Direito (LAGAZZI, 1988, p. 46).

O desfecho do texto baliza e questiona a máxima dos "direitos e deveres" (contribuição do juridismo). Partindo deste princípio, os "trâmites burocráticos", afirma Orlandi, fazem valer a ordem da forma-sujeito capitalista, uma vez que a burocracia não garante, em seu funcionamento, a democracia. Para a autora, a simbolização do político, no processo discursivo, acaba silenciada enquanto a burocracia assume os espaços administrativos, saturando a própria possibilidade de haver direitos.

Na continuidade encontramos a contribuição de Flávio da Rocha Benayon com $A$ condenação de manifestantes nos protestos de 2013: considerações sobre o funcionamento do discurso jurídico, na qual o autor busca analisar a sentença proferida pelo MPRJ (Ministério Público do Rio de Janeiro) no ano de 2018, que condenou à reclusão de 23 (vinte e três) manifestantes dos protestos de 2013 - protestos marcados por uma maciça recusa “à classe política”. De Suzy, Benayon mobiliza o legado sobre o 
discurso jurídico, essencial às suas pretensões analíticas. Com isso, considera a presença das relações econômicas (capitalistas) e sociais (de classe) na produção do discurso jurídico, no qual a historicidade é apagada como condição para o funcionamento da máxima "direitos e deveres" que constitui o sujeito-de-direito e a evidência de sua pretensa "autonomia". À vista disso, Benayon colocará em causa o julgamento de quatro sujeitos manifestantes alvos da sentença condenatória: Sininho, Júnior, Marino e Moa. Por meio de seu gesto de interpretação, explicita a (falta de) "neutralidade" do aparelho jurídico, assim como insiste na "autonomia de si" e na "captura universal" como característica do sujeito-de-direito instituído no discurso da instância jurídica. Detalhado, o movimento analítico aponta para diferentes direções; chama-se a atenção, de sobremodo, ao apagamento da massa no protesto, por meio da captura da "individualidade" dos manifestantes na sentença do MPRJ. Conforme Benayon, esse processo faz com que as reinvindicações da maioria (massa) sejam apagadas e sobrepostas a outros sentidos, isto é, a manifestação passa ser ressignificada como associação criminosa e/ou crime. Acuados pelas sentenças, os sujeitos são individualizados no discurso jurídico.

Já em $O$ juridismo e o desafio de dizer diferente, Solange Leda Gallo reencontra, nos passos de sua trajetória, as pegadas de Suzy. Sobressai-se, no relato de Gallo, o caminho dividido com Lagazzi, coincidente com o começo definidor do fazer Análise do Discurso no Brasil, na década de 1980. Partindo ao seu objeto de reflexão, Gallo, assim como outros autores da seção, mobiliza a noção de juridismo. O objetivo da autora é apreender a especificidade do funcionamento do sujeito inscrito na "função autor" no espaço virtual (espaço em que os discursos de escritoralidade - conceito desenvolvido por Gallo - constituem fortemente as práticas de interlocução). Na produção do gesto analítico, Gallo retoma trabalho anterior em parceria com Silveira (2017), no qual buscavam compreender a formulação de dizeres no microblog Twitter. A autora interroga, então, um tuíte de Gilmar Mendes (ministro do Supremo Tribunal Federal - STF), qualificando-o como insertado no discurso de escritoralidade e, por isso, acarretando consequências à legitimidade do discurso jurídico (escrito, institucionalizado, normatizado) que não encontra correspondência no espaço virtual. Em um dos pontos de chegada, Gallo destaca que o juridismo no espaço informatizado, “[...] se formula sem uma aparente tensão, já que a formulação é pré-determinada pelo espaço informatizado e garante o espaço e a forma de dizer, sem contradições" (GALLO, 2019, p. 79). Ao fim, Gallo alerta que o discurso de escrita e sua legitimidade são desestabilizados no virtual. 
Prosseguindo, Olimpia Maluf-Souza escreve o texto A função-autor nos laudos de comprovação de higidez mental. A pesquisadora expressa o carinho e a admiração que nutre pela homenageada, posto que Maluf-Souza foi a primeira orientada de mestrado e de doutorado de Suzy. Em nome do afeto, a pesquisadora tira da gaveta um texto arquivado de sua época de pós-graduanda. Retornando a sua trajetória de mestrado, Maluf-Souza volta a colocar em questão o discurso dos criminosos-loucos em laudos periciais (atravessados pelo discurso jurídico e médico). O texto, consoante a autora, foi reescrito com um olhar amadurecido. Como objeto de análise, Maluf-Souza escolhe como exemplo o caso do Maníaco do Parque (cf. Maluf, 2019) e grifa que é a posição-autor nos laudos de comprovação de higienização mental, como no Maníaco do Parque, que lhe importa na análise. A pesquisadora argumenta, em sua análise, que os peritos, como intérpretes da loucura, atribuem aos criminosos-loucos o sentido de loucura como oposição a normal, num diagnóstico pré-estabelecido. Deste modo, a autora evidencia a contradição existente entre discurso médico-legal e o discurso do periciando.

Guilherme Adorno, em $\mathrm{Na}$ Dança das imbricações ou uma coreografia materialista: o discurso nas fronteiras traz, com vigor, uma contribuição de grande valor à história das ideias "discursivas", isto porque na homenagem que dirige à Suzy rememora com afeto e precisão técnica a travessia teórica da autora. No regaste arquitetado por Adorno, a trajetória intelectual de Suzy se demonstra como contemporânea à própria história da AD no Brasil. Minucioso, o autor qualifica o que considera especialidade da produção intelectual de Suzy: o Direito e a Análise de diferentes materialidades significantes. A partir dessas fontes, imbricam-se as noções de materialidade significante, de composição e de imbricação, as quais Adorno apresenta com sutileza. O trabalho com documentários, filmes e imagens proporcionará à Suzy, conforme o autor, encontrar vias capazes de lhe permitir chegar à especificidade do funcionamento do imagético. $\mathrm{O}$ caminho percorrido por Suzy é, desta forma, marcado por uma heterogeneidade pulsante, seja no trabalho com o imagético, com a análise do cotidiano (juridismo), na implicação da forma-sujeito-de-direito nos processos discursivos ou na formulação da resistência simbólica. Assim sendo, Adorno apresenta, em seu texto, como a própria força de Suzy é emprestada à $\mathrm{AD}$ para a constituição de suas querelas. Não restam dúvidas que o texto de Adorno pode servir como porta de entrada e apresentação aos que não conhecem Suzy.

No desfecho da seção, encontramos Carolina Rodríguez-Alcalá com o texto: “ $D a$ evidência do espaço à evidência da percepção sensível: uma abordagem discursiva”. 
Rodríguez-Alcalá estabelece um paralelo entre o saber urbano e a linguagem, para isso, busca desconstruir a evidência do espaço - retificação em relação à evidência de mundo, tratada em trabalhos anteriores. Lança mão das categorias de evidência do sujeito (Althusser, Pêcheux) e de evidência da linguagem (Orlandi) para chegar a uma terceira evidência, a evidência de espaço, caracterizada como: “[...] ilusão subjetiva pela qual o espaço de vida humano se apresenta como um cenário neutro, exterior e anterior à constituição dos sujeitos e dos sentidos" (ibidem, p. 136). Elucidativa, a reflexão de Rodríguez-Alcalá demonstra - com o auxílio de esquemas explicativos - que na produção do espaço há a imbricação da história, do simbólico e do político, descortinando as evidências que tomam sujeito, linguagem e espaço.

Na sequência, encontramos a segunda seção intitulada $A$ imbricação de diferentes materialidades significantes que conta com textos que, retomando a obra da homenageada, mobilizam especialmente a noção de materialidade significante. Este constructo teórico adquire status de contribuição fundamental para ler e compreender Suzy, posto que sob seu interstício é possível compreender o discurso verbal por uma via materialista do sentido - outra fronte de trabalho singularmente desbravada por Suzy. A seção conta com quatro artigos.

O primeiro artigo a figurar na seção é Na delicadeza da prática teórica e analítica de Suzy Lagazzi: um recorte, cuja autoria fica por conta de Cláudia Castellanos Pfeiffer. A autora, com sútil amabilidade, narra com emoção o primeiro encontro que teve com Suzy, voltando a atenção para o que construíram juntas depois desse contato. A apresentação de Suzy por Pfeiffer é explicativa e didática. Assim como os outros autores, Pfeiffer faz reluzir a força intelectual de Suzy, computando ao juridismo e ao funcionamento da metáfora e da metonímia, alguns dos grandes acertos teóricos da homenageada. Ainda nessa lista, enumera a imagem e a noção de materialidade significante como lugar de investimento teórico de Suzy. Outro detalhe que a pesquisadora chama a atenção é ao modo como Suzy trabalhou intensamente "para que novas práticas de análise pudessem se instalar com consistência teórico-epistemológica” (PFEIFFER, 2019, p.148). Nessa direção, esclarece que houve uma insistência especial de Suzy, por exemplo, no processo de identificação do sujeito (como constituição simbólica) e ao que aos olhos de Pfeiffer consiste no âmago para o projeto intelectual da AD no Brasil: a noção de resistência simbólica.

Rômulo Santana Osthues em Um decalque da cena prototípica: corpo, panela e nariz de palhaço (re)traçados na memória faz uma análise precisa de imagens dos 
protestos de 2015, marcados pela efusão do antipetismo que saiu às ruas exigindo a saída da então presidente da República, Dilma Rousseff. Seu foco de reflexão é a cena prototípica - trabalho do interdiscurso no atravessamento com o intradiscurso -, própria à materialidade visual. A formulação de cena prototípica, dirá Osthues, é mais uma das intervenções de Suzy nos estudos do discurso na direção de apreender as faces na constituição do imagético. $\mathrm{O}$ autor destaca como seu gesto de leitura se faz frente à imagem. Considera, para tal, a paráfrase como meio de apreender o funcionamento do efeito metafórico (fundamento basilar na compreensão do discurso) que constitui seus objetos de análise, isto é, uma fotografia do protesto de 2015 e seu efeito parafrástico em uma charge publicada em 2016. As duas cenas são atravessadas pelo dizer do nariz de palhaço, da panela (protesto) e do corpo, o que faz Osthues defender que a relação do palhaço (instaurada pelos sentidos investidos no sujeito em protesto) se traça numa historicidade "imbrincada", já que o sujeito assume, em seu corpo, a presença de algo outro. O texto é arrematado com uma terceira cena, na qual o sentido de palhaço e de panela derivam para outro lugar, agora em defesa de Rousseff (2015). Assim sendo, ao mobilizar a cena prototípica, Osthues chama atenção para sentidos que se cruzam e se opõem a partir da historicidade e da posição que os sujeitos se inscrevem na cena do protesto.

Em seguida, Emanuel Angelo Nascimento apresenta: Um (per)curso en(tre)laçado entre diferentes materialidades significantes. No texto, Nascimento coloca em evidência três tipos de corpos em protestos: mulheres do Femen (na França, 2015), sufragistas (suffraGETtes, Inglaterra, começo do século XX) e ativistas afroamericanas pelos direitos da população negra no auge da repressão e segregação racial nos Estados Unidos (segunda metade do século XX). Conforme o autor, o recorte busca entrelaçar a noção de materialidade significante à “[...] análise de imagens do social, pensando como o corpo feminino se coloca enquanto feminista" (NASCIMENTO, 2019, p. 206). Em seu gesto de análise, Nascimento procura demonstrar a tensão entre os sujeitos (mulheres manifestando no/pelo feminismo) e as condições de produção em que estão condicionados, o que leva-o a observar o equívoco na relação com os sentidos de segurança/violência que participam da formulação do corpo em protesto: a posição, a inscrita de sinais gráficos, o espaço, o entorno, a repressão polícia, etc. O pesquisador, tomando a escuta do social a partir da história, apreende o entrelaçamento do ato de 
protesto se atravessando e se constituindo nas posições ocupadas pelos corpos em protesto, desde as sufragistas até as feministas contemporâneas.

Luciana Leão Brasil encerra a segunda parte com seu texto Na análise de discurso os discursos em análise: indo além do mais além. A pesquisadora opta por retomar o projeto de análise do discurso proposto por Pêcheux para então situar como o fazer AD no Brasil foi afetado pela presença de Suzy. Nessa direção, são situadas as contribuições de Suzy quanto às reflexões em torno do discurso visual e verbovisual, especificidade que pulsa no terreno da $\mathrm{AD}$ como objeto inerente à própria compreensão de discurso. Retomando a distinção teórica feita por Suzy, isto é, formulação visual e imagem, salienta que o entrecruzamento do verbal e do visual se faz em materialidades distintas e que esse labor teórico é visível em todas as análises desenvolvidas por Suzy, seja em filmes ou documentários: Boca de lixo (1993), Tereza (1993), Território Vermelho (2004), Atos dos Homens (2005), Era uma vez (2007), Tropa de Elite (2007), Última Parada 174 (2008). Leão enumera com primor as contribuições de Suzy a partir do visual, deixando claro que a maior preocupação da homenageada no trabalho com o discurso imagético é compreender o recorte do social no visual, vide o repertório analítico tomado por obras com cunho de crítica social. Explicitar o trajeto analítico de Suzy torna o trabalho de Leão especialmente relevante: nas pegadas das apresentações, encontramos o trajeto intelectual de Suzy.

A terceira e última parte, Resistência simbólica, traz contribuições de Renata Marcelle Lara, Luiz Carlos Martins de Souza e Carolina Padilha Fedatto. Os autores buscam, em proposições particulares, dar corpo a reflexões no campo da arte e do social. A narratividade e a demonstração visível da influência de $S u z y$, no caminho seguido pelos escritores da seção, é incontestável.

Na contramão dos textos do primeiro volume, Renata Marcelle Lara decide pela provocação em seu artigo $O$ olh(o)ar (d)a imagem-quadro: o semblante (de) Marielle. A influência da psicanálise é pungente na reflexão de Lara, que, recorrendo à Lacan, estabelece uma aliança com o campo da arte (Didi-Huberman), sob a "efígie midiática" de Marielle, vereadora pelo Rio de Janeiro assassinada em 2018. Tecendo numa breve narração (a vida de) Marielle, Lara busca apreender, a partir da psicanálise, como o semblante, a imagem-quadro da vereadora morta, ecoa na mídia. Marielle, exposta em quadros midiáticos, se faz significar na medida que algo do social é dito pela/em sua ausência, funcionando em "imagens-semblantes" que são "imagens inconscientes no social” da política. As efígies - imagens-visuais-, estão imbuídas no simbólico como 
meio de resgatar Marielle, sua morte, seu trabalho, sua importância na luta política. Relações que, como lembra Lara, estão textualizadas, materializadas nas notícias e nos noticiários (televisivos ou virtuais). Há, dessa forma, uma presença inconsciente do quadro-imagem de Marielle que passa a constituir memórias e resistências no tecido social.

Luiz Carlos Martins de Souza em Por um método de análise de obras artísticas: uma proposta na perspectiva discursiva a partir do RSI trilha o mesmo caminho de Lara: aventurar-se pelo diferente. A Amazônia, lugar de trabalho do autor, é reverenciada como espaço para produção da sua proposta de análise da arte, fruto de discussões travadas ao longo de sua trajetória acadêmica. Para desenhar a proposta, apresenta os caminhos metodológicos que deve seguir, adentrando o discurso científico para discernir a proposta. Nas palavras de Souza (2019, p. 255), seu objetivo consiste em "[...] a partir das categorias lacanianas do Real, Simbólico e Imaginário (RSI), propor uma metodologia para análise de obras artísticas a partir da noção de materialidade significante". Mobilizando essa noção, inicialmente proposta por Suzy, Souza pretende compreender o funcionamento e a textualização de obras de arte (produtos estéticos), considerando como determinante as condições de produção amplas na constituição/formulação dos objetos de análise. O autor recorre à ideia da arte, a desnuda (já que esse é seu objeto privilegiado em sua proposta), para então apontar os procedimentos que considera pertinentes para o movimento reflexivo correlacionados ao RSI. Assim sendo, Souza acredita que a desautomatização abrirá espaço a partir do trabalho com o RSI, possibilitando a apreensão da tessitura do corpo da arte. O pesquisador deixa claro que se trata de um projeto, de uma nova proposição, que não é totalizante, mas está aberta à exploração.

No encerramento do primeiro volume, nos deparamos com Carolina Padilha Fedatto, em $O$ desafio de dizer eu (analogia ao livro de Suzy, O desafio de dizer não). Fedatto narra com sentimento e emoção a trajetória e a influência de Suzy na sua formação. Resgata, no caminho do afeto, o contexto de formação do grupo que leva o nome do primeiro e segundo volumes "O discurso nas fronteiras do social". Ressalta a preocupação do grupo com as formas da denúncia social e os modos de resistência simbólica que integram os grandes empreendimentos teóricos de Suzy. A imagem, dirá Fedatto, integra o percurso do grupo e de Suzy. Em homenagem à Suzy, a autora lança-se a refletir o atravessamento na denúncia da imagem. Para tanto, debruça-se na fotografia A execução de Eddie Adam, que retrata um prisioneiro de guerra, vietcongue, sendo 
morto acusado de supostos assassinatos contra americanos e sul-vietnamitas, no contexto da Guerra do Vietnã. Fedatto busca, na análise, o lugar do $e u$ na fotografia, que se conta a partir do "horror do outro" mesclado em "formas do testemunho e da autoria" (FEDATTO, 2019, p. 298). A pesquisadora enfatiza o entorno da fotografia, o retrato da guerra, o encontro com a morte, o choque do próprio real que toma o corpo com o fim da vida. Ao final da bela e delicada análise, Fedatto diz que "como um balanço provisório e emocionado das lições que não mais deixei de praticar a partir da força de convivência com Lagazzi, gostaria de reafirmar esta: dizer eu, com todos os riscos, toda coragem, toda paixão que assumimos na relação com o discurso" (ibidem, p. 310).

Para além da homenagem, $O$ discurso nas fronteiras do social: uma homenagem à Suzy Lagazzy - volume I, consiste numa produção que contribui de forma nodal à história das ideias linguísticas/discursivas no Brasil. A homenagem, ademais de destacar a potência de Suzy Lagazzi, recompõe uma trajetória intelectual que coincide com o enraizamento da análise de discurso pecheutiana como forma incontornável de teorizar o discurso em solo brasileiro. Além disso, pudemos perceber que através do olhar delicado que dirige ao social, formou incontáveis pesquisadores que generosamente a homenageiam. Concluo o texto com duas formulações chaves: 1. de todos nós que nos designamos "Analistas de discurso" a leitura de Suzy é elementar; 2. se alguém para além de Eni Orlandi encarnou com força e, sem medir esforços, o projeto intelectual da Análise de Discurso no Brasil, esse alguém foi Suzy Lagazzi.

\section{Referências bibliográficas:}

ADORNO, Guilherme; MODESTO, Rogério; FERRAÇA, Mirielly; BENAYON, Flávio; ANJOS, Liliane; OSTHUES, Rômulo. (Orgs.). O discurso nas fronteiras do social: uma homenagem à Suzy Lagazzi - volume 1. Campinas, SP: Pontes Editores, 2019.

LAGAZZI, Suzy. O desafio de dizer não. Campinas, SP: Pontes Editores, 1988. 


\section{Para citar essa obra:}

Ragievicz, Matheus França. Suzy Lagazzi ou um guia à Análise de Discurso. In: RUA [online]. Volume 26, número 1 - Ahead of print - e-ISSN 2179-9911 -jun./2020. Consultada no Portal Labeurb - Revista do Laboratório de Estudos Urbanos do Núcleo de Desenvolvimento da Criatividade.

http://www.labeurb.unicamp.br/rual

Capa: capa do livro $\mathrm{O}$ discurso nas fronteiras do social: uma homenagem à Suzy Lagazzi - volume 1. Pontes Editores, 2019.

Laboratório de Estudos Urbanos - LABEURB

Núcleo de Desenvolvimento da Criatividade - NUDECRI

Universidade Estadual de Campinas - UNICAMP

http://www.labeurb.unicamp.br/

Endereço:

LABEURB - LABORATÓRIO DE ESTUDOS URBANOS UNICAMP/COCEN / NUDECRI

CAIXA POSTAL 6166

Campinas/SP - Brasil

CEP 13083-892

Fone/ Fax: (19) 3521-7900

Contato: http://www.labeurb.unicamp.br/contato 